\title{
Influence of diabetic polyneuropathy on the severity of pain in patients with osteoarthritis of the knee joints and type 2 (iil $\approx$ diabetes mellitus.
}

\author{
L. Strongin, K. Korneva, E. Trifonova
}

Nizhny Novgorod State Medical Academy, Nizhny Novgorod. Russia

\section{Background}

Osteoarthritis (OA) and type 2 diabetes mellitus (T2DM) are common diseases among middleaged and elderly persons. OA is noted in each third patient at the age from 45 to 64 years old and in 60$70 \%$ patients older than 65 [1]. The leading symptom in $O A$ is pain. That's why it is necessary to study the role of the most common complication of T2DM - DPN on coursing of $O A$ for the reduction of symptoms, as well as improve the quality of life and prevent loss of disability for these group of patients.

\section{Objective}

To assess the influence of diabetic polyneuropathy (DPN) on the severity of pain in $O A$ in patients with concomitant T2DM.

\section{Methods}

80 female patients with OA of the knee joints in combination with T2DM were examined. The severity of gonarthrosis were assessed by Lequesne index (IL) (version 1997) using a valid questionnaire [2]. Neurological examination included the use of the electroneuromyography.

\section{Results}

The patients were divided into 2 groups depending on the results of motor conduction velocity (MCV) of $n$. Peroneus and sensory conduction velocity (SCV) of n.Suralis. Group 1 consisted of patients with normal MCV/SCV, Group 2 - reduced.

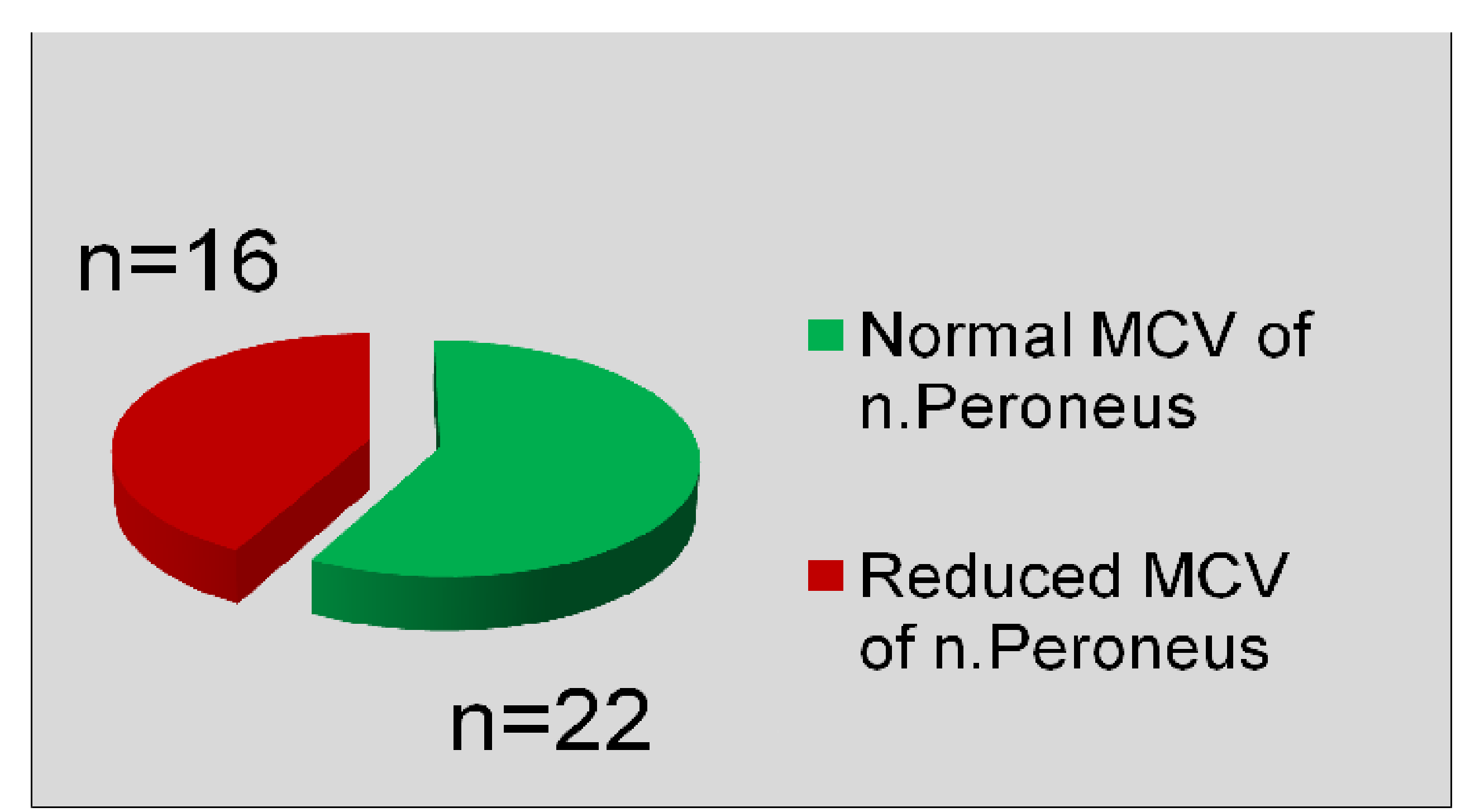

Fig.1. The contingent examined patients with normal and reduced MCV of n.Peroneus

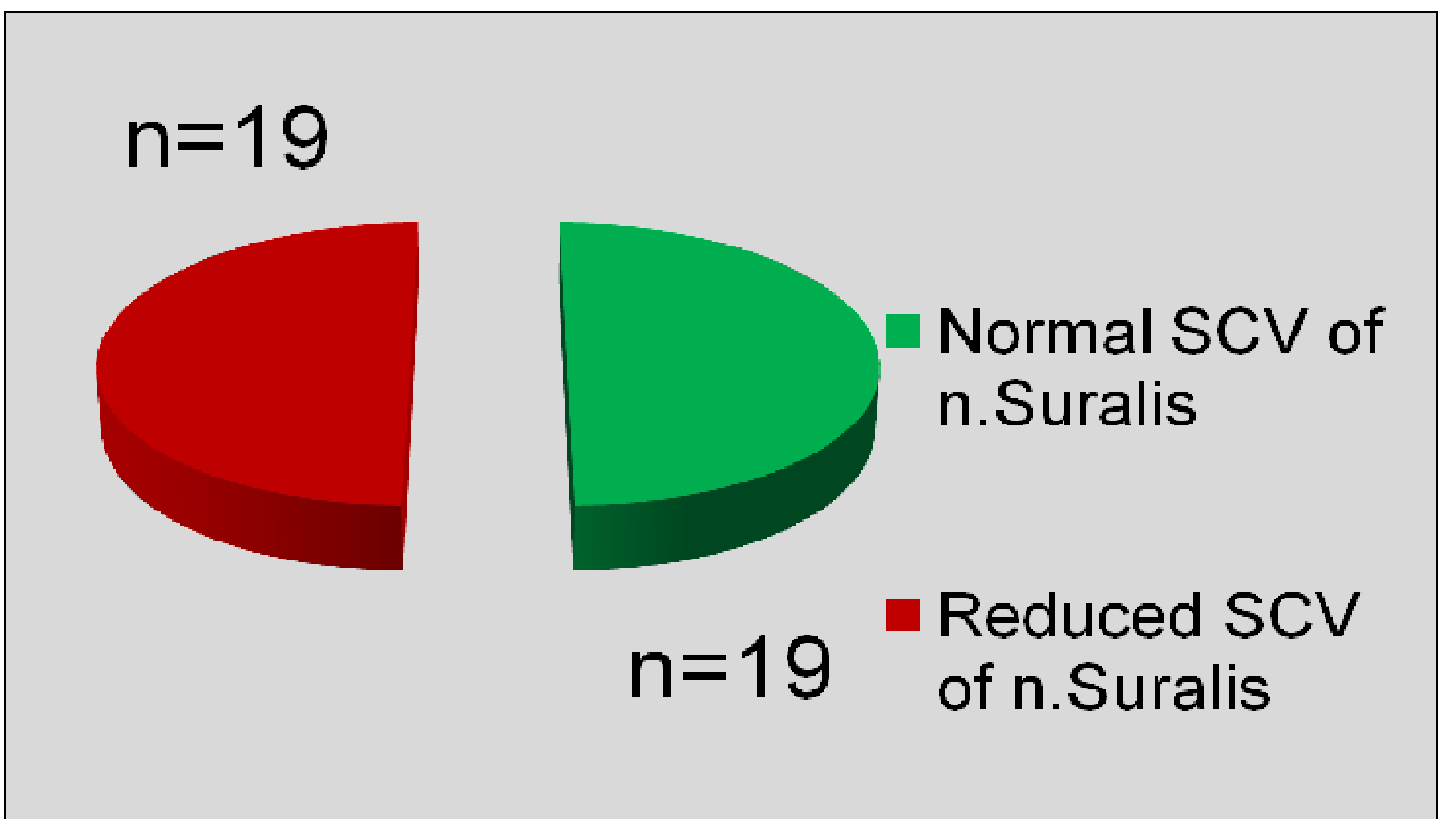

Fig.2. The contingent examined patients with normal and reduced MCV of $n$.Suralis

In group 1 with normal MCV values on n.Peroneus more prominent pain associated with inflammatory changes in the knee joints by IL were noted: nocturnal pain in the knee joints was $1.32 \pm 0.78$ vs. $0.81 \pm 0.66$ points in group 2 $(p=0.04)$, the ability to kneel 1.73 \pm 0.46 vs. $1.26 \pm 0.45$ points $(p=0.01)$.

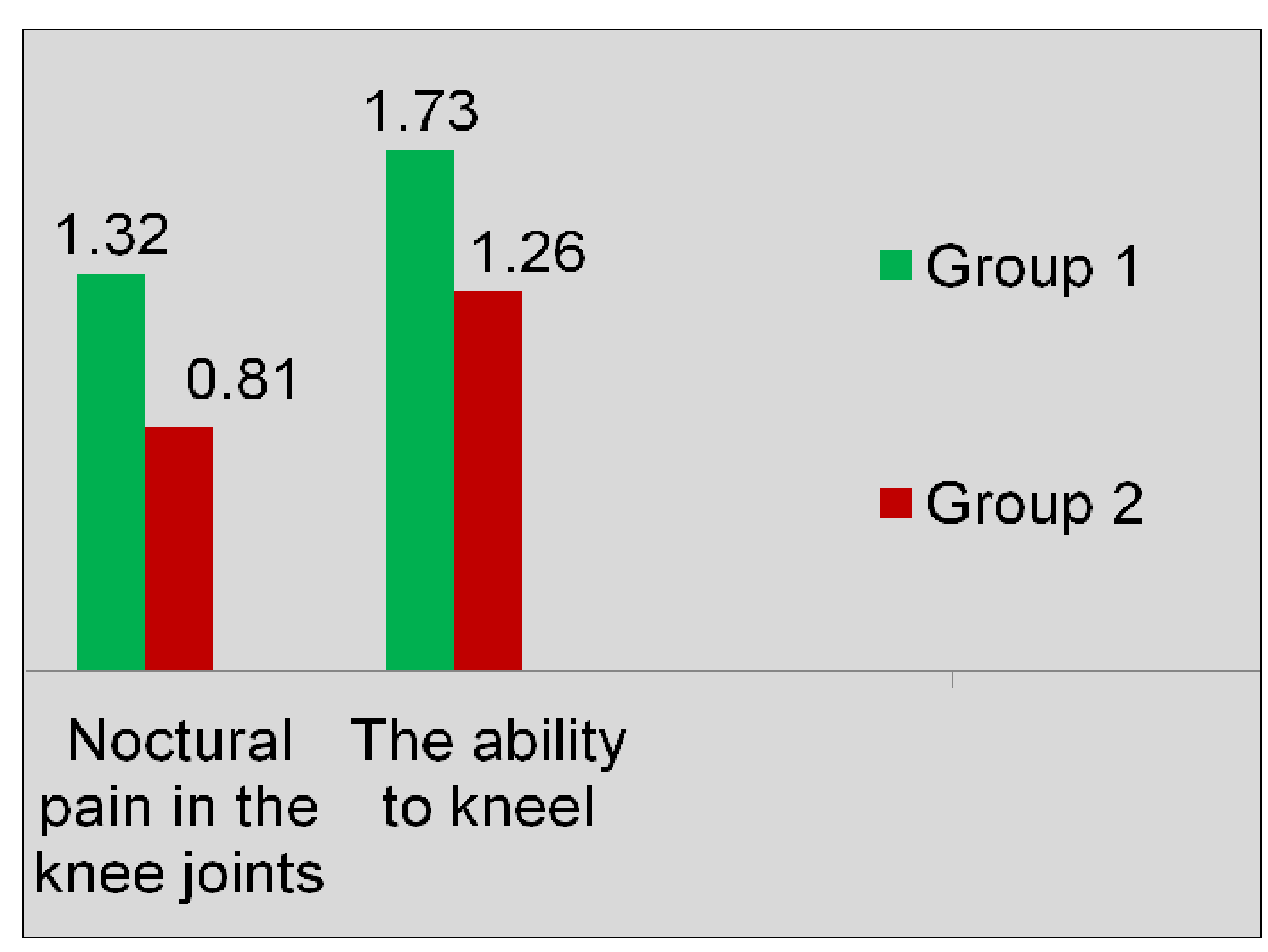

Fig.3. The symptoms of OA according the IL in the group with normal and reduced MCV of n. Peroneus
In contrast functional disorders (the intensity of pain during the descent 1 flight of stairs) were more pronounced in group $2-1.26 \pm 0.45$ vs. $0.8 \pm$ 0.68 points in group $1 \quad(p=0.02)$. Reduction of SCV on sensory fibers of $\mathrm{n}$.Suralis intensified pain when walking: in group $1-0.95 \pm 0.40$ vs. $1.32 \pm 0.58$ points in group 2 $(p=0.03)$.

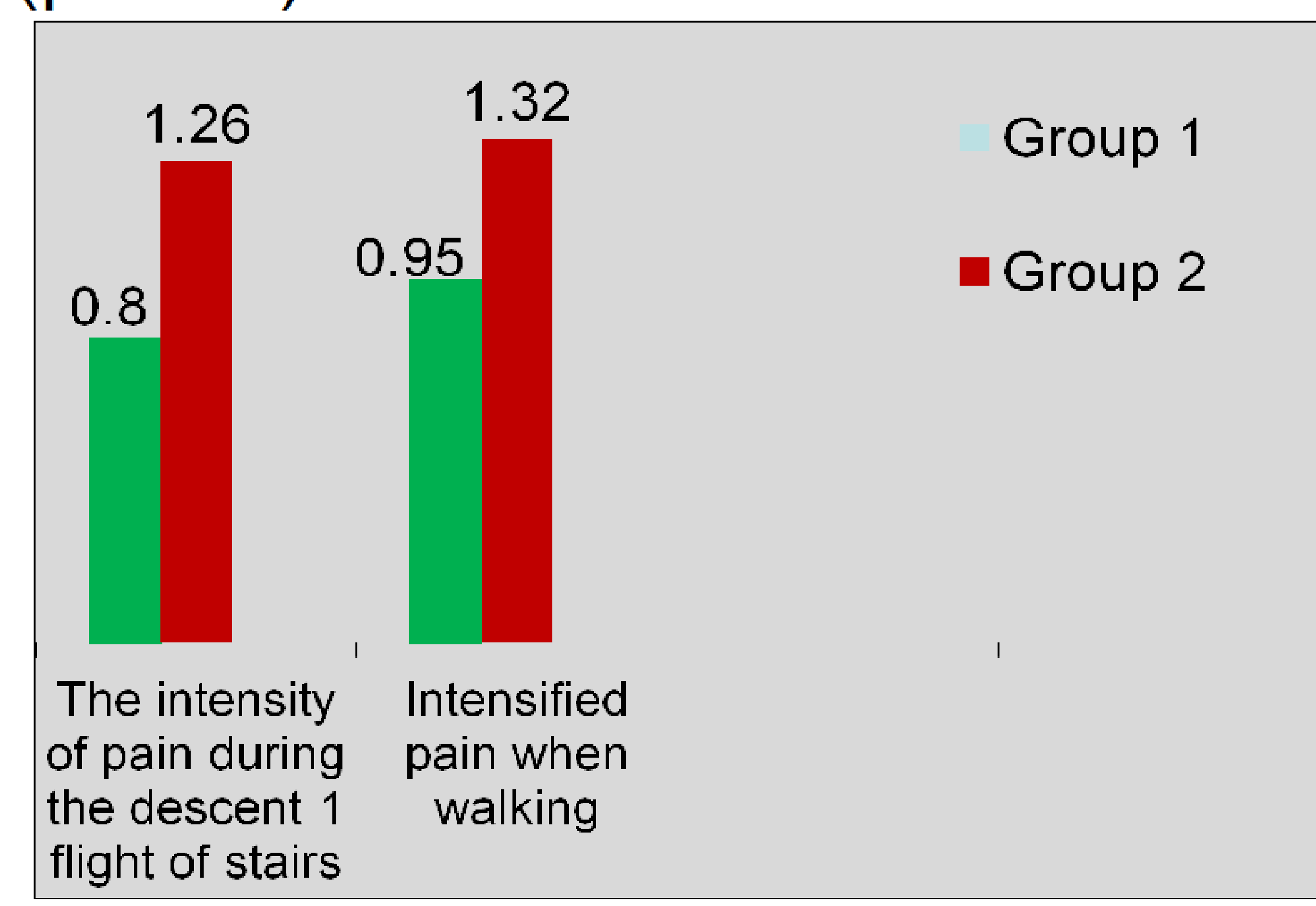

Fig.4. The symptoms of OA according the IL in the group with normal and reduced SCV of n. Suralis

\section{Conclusions}

DPN was associated with changes in OA pain perception dependent on involvement of motor and sensory fibers. Decreased MCV masked pain associated with inflammatory changes in the knee joints. On the other hand, functional disorders associated with degenerative-dystrophic changes in OA were more marked by damage of both sensitive and motor fibers.

\section{References}

Arden N., Nevitt M.C. Osteoarthritis: Epidemiology. Best Practice \& Research Clinical Rheumatology. 2006; 20(1) $3-25$

2. Lequesne M.G. The algofunctional indices for hip and knee osteoarthritis. J Rheumatol. 1997; 24: 779-781. 